\title{
The use of natural history dioramas for science education
}

\author{
Michael J. Reiss
}

\begin{abstract}
Natural history dioramas have long been identified as potentially valuable sites of learning. In this chapter, I first examine what the purposes of science education might be and then argue that the other chapters in this book shows that natural history dioramas do indeed have considerable potential to advance the learning of science. Such dioramas are engaging to many visitors, whatever their age and prior knowledge and experience and enable visitors to construct narratives about what is happening in the diorama. Nevertheless, the evidence about the extent and types of learning that natural history dioramas can enable is still modest. Furthermore, there exists quite a wide range of tools for gathering and interpreting data at dioramas and it is not always evident that the reasons for this diversity are valid. Much research still needs to be undertaken to help realise the educational affordances of natural history dioramas.
\end{abstract}

\section{Keywords}

natural history dioramas, science education, aims of education, museums

\section{The purposes of science education}

There are a number of aims for science education (Reiss, 2007) though these are often implicit. A frequent aim of many school science courses, and an aim supported by governments and industry, has been for them to provide a preparatory education for the small proportion of individuals who will become future scientists (in the commonly understood sense as employed professionals). This aim, though important economically, has been critiqued on democratic grounds (e.g. Millar and Osborne, 1998). After all, what of the large majority of school students who will not become such scientists?

Another aim of science education, whether it takes place in schools or not, is to enable 'scientific literacy'. Although there has been a long-running debate as to the meaning of the term (e.g. Miller, 1983), generally scientific literacy is seen as a vehicle to help citizens understand scientific issues. The basic notion is that science education should aim to enhance understanding of key ideas about the nature and practice of science as well as some of the central conclusions reached by science.

Many science courses in schools, colleges and universities hope that students will be able themselves to benefit materially from the science they have learnt. At its most straightforward this might be by entering or being in paid employment where the work that individuals undertake draws on what they have learnt of science. Although, as noted above, most school students do not enter such careers they too may still benefit individually from the science they have learnt whether inside or outside of school. For example, in most science courses, in countries around the world, it has long been accepted that one of the justifications 
for the inclusion of certain topics is that knowledge and understanding of them can promote human health.

With John White, I have argued that that school education should equip every student to lead a life that is personally flourishing and to help others to do so, too (Reiss \& White, 2013). This aim applies to science education as much as to other subjects. Indeed, it is rather easier to see how school science might meet this aim than is the case for some other school subjects.

Whatever the agreed aims of science education, and whether we restrict ourselves to schoolaged learners or to others, my contention is that natural history dioramas have a small but significant role to play in meeting the aims of science education. In this, the concluding chapter to this book, I examine the key arguments and conclusions of each of the other chapters, concentrating on the extent to which natural history dioramas are indeed known to help meet the aims of science education.

\section{Fashion and dioramas}

Natural history dioramas have a long history in many countries; indeed, as discussed by Rogers, Shreckengast and Dorfman in Chapter 1, their origins can be traced to the late $18^{\text {th }}$ century presentation of taxidermy specimens by Charles Willson Peale within a recreated, natural environment. Peale soon abandoned this new approach, probably because the uncased animals were subject to damage by insects, patrons and sunlight (problems that remain to this day), but others took up the reins. Important among these, though overlooked till now in major publications detailing the early history of dioramas and habitat groups in the United States, was another taxidermist - James A. Hurst. From the 1850s, Hurst used his own extensive collection of birds and beasts of North America to produce stereoscopic views. These offered the public an innovative way to view a representation of the natural world from the comfort of their homes. Whether these paintings, combined with a taxidermy mount and recreated foreground, were permanent exhibits is unknown.

Despite this long history, dioramas went out of fashion towards the end of the twentieth century in the USA and in many countries. Fashion is a funny thing. One is reminded of how Andrew Lloyd Webber' grandmother responded "I will not have Victorian junk in my flat" when her grandson begged her in the early 1960 s to lend him $£ 50$ so that he could buy Lord Leighton's Flaming June - now known as the Mona Lisa of the southern hemisphere. (Years later Webber offered $£ 6 \mathrm{~m}$ for it but was turned down.) In the case of dioramas, they seem to have been become seen as old-fashioned compared with the glitzy allure of interactive exhibits and other 'modern' methods of display. Their problem was precisely that they were objects for education. A museum isn't likely to destroy what it considers to be historical objects of cultural importance however fuddy-duddy they look but will happily consign to the skip the work of craftsmen who labored for hundreds of hours to produce a single diorama for educational purposes.

It's too early to say that the tide has turned but dioramas are making something of a comeback, despite their cost. They are often much loved by visitors of all ages and, as the other chapters in this volume discuss, have considerable educational potential.

\section{Developing and maintaining dioramas}


Our relationship with wolves is a complicated one. While some see wolves as a persecuted species, now rare or extinct in many countries, so that we have conservation responsibilities to them, others see them as pests, others as dangerous, others as the rather bored inhabitants found in wildlife sanctuaries, others as the ancestor of 'Man's best friend' and others as more general reservoirs of cultural resonance - e.g. the story of Little Red Riding Hood (Reiss \& Tunnicliffe, 2011). All of these possible readings are open to a viewer seeing an isolated wolf but, as Karen Wonders (1993) points out, a natural history diorama encourages some readings at the expense of others.

In Chapter 2, Andrew Kitchener tells the story of his role in the development of a new diorama, wolves and all, that deals with the biological history of Scotland since the end of the last Ice Age. He points out that many dioramas show animals just standing or looking back at the observer. He wanted to show animals displaying dramatic natural behaviours and interacting with each other, in ways that highlighted key adaptations, behaviours or interactions between species. He also wanted to show not just the big changes from tundra at the end of the last Ice Age to the peak climax forests of up until about 5,000 years ago (when Neolithic farmers began to change the natural landscape dramatically and permanently), but also changes on a seasonal and daily timescale.

From an educational perspective, one of the difficult decisions was whether to show people or not. In the end, people were excluded partly because the Mesolithic human story is told in an adjacent gallery and partly because it was felt that there was no way of knowing what clothes people would have worn at the time. However, there is a very small snowman though the visitor has to look from the right vantage point to see him. Evaluation to date has been somewhat limited (Tunnicliffe, 2005), though from the two occasions I have visited the diorama I can vouch for the affection in which it is evidently held, especially among younger visitors.

In Chapter 3, Eirik Granqvist reflects on his experiences of the construction of dioramas in the Zoological Museum of the University of Helsinki, beginning with one that shows a fight between elk (Alces alces) in the autumn rut. He researched their behaviour and spent three years before he found the specimens, which he shot himself, that he wanted. Comparable care was taken over the other organisms, the painting of the background, the lighting, the viewing angle and the size of the window.

Granqvist states bluntly that the greatest danger to dioramas comes from museum staff who are not competent or knowledgeable in diorama construction and maintenance. After that, the chief problem is insects - as also noted by Kitchener in Chapter 2 - since clothes moths came close to running the diorama only a few years after it had opened. There is a certain poignancy to Granqvist's comments about museum staff as his own dioramas in the Zoological Museum of the University of Helsinki no longer exist, having been dismantled.

\section{The educational significance of natural history dioramas}

As becomes clear on reading the chapters in this volume, despite some impressive exceptions, many of them undertaken either by Sue Dale Tunnicliffe herself or by colleagues or doctoral students of hers, the educational significance of natural history dioramas remains considerably underexplored. 
An example of this lack of exploration is provided in Chapter 4 by Rainer Hutterer and Till Töpfer. Despite titling their chapter 'Dioramas of marine bird colonies: history, design, and educational importance', the material on educational importance is really about educational potential. For a case study, they focus on the Bird Rock on Bear Island diorama, found in the Museum Koenig in Bonn and constructed from 1912-1933. Bear Island lies between Spitsbergen and the Norwegian North Cape. Koenig made a number of visits to the Spitsbergen archipelago and was fascinated that its bird fauna was still relatively unexplored. Scientific publications, authored by Koenig and others who accompanied him, resulted for Bear Island and Spitsbergen.

The bird rock diorama is impressive in its scale: it stands some $5 \mathrm{~m}$ and, despite a number of changes to its lighting over the years, is still in much its original form and benefited from a thorough renovation in 2006. In all there are 98 birds belonging to a total of nine species.

Hutterer and Töpfer discuss the educational potential of the diorama. Clearly the visitor can learn much about bird morphology, including adaptations for flight and the existence of two plumage morphs in the common guillemot (Uria aalge), as well as about seabird diversity, breeding ecology, egg characteristics, feeding ecology and the importance of rock islands for bird conservation, not to mention expedition history. Hutterer and Töpfer suggest that additions could be made to enhance the educational value of the diorama; for example, there could be an acoustic background with sound recordings from a bird rock colony on Bear Island, or live pictures from a remote webcam from a seabird colony somewhere in Europe.

A different approach is adopted in 'miniature dioramas', of which a number of botanical examples exist. In Chapter 5, Kathrin Grotz discusses the sixteen small vegetation dioramas (with a scale of 1:10 or 1:20) in the Botanical Museum in Berlin. In passing we can note the extraordinary amount of time and effort that was spent on constructing these dioramas: for example, the three alder trees standing at the 'Lake of the North German lowland' required 12,000 custom-made miniature sheets of painted copper sheet. However, while the aesthetic and emotional value of the dioramas is undisputed, most visitors to the Botanical Museum find it difficult to understand what they convey. Grotz discusses how these dioramas can be updated to make them more intelligible to visitors.

In Chapter 6, Alexandra Moormann and Charlène Bélanger point out that since they were first produced, natural history dioramas have always been intended to trigger learning among visitors about biological topics such as animal behavior and ecosystems. In their work, they look at dioramas as simplified models of natural ecosystems and seek to answer two questions: To what extent can dioramas be considered scientific models? How can dioramas promote model-based learning?

Moormann and Bélanger point out that before the appearance of dioramas, natural science museums were mainly concerned with the exhibition of objects from their collections, organised according to the structure dictated by the understanding of the natural order that was dominant at that time in the scientific community. By seeing dioramas as models, we can appreciate that dioramas are not meant to show reality 'as it is' since this is not the function of a model. Rather, a model inevitably embodies a reduction and particular refraction of reality. Accordingly, a diorama, like a model, will present different features depending on intentions of their creator. 
Furthermore, models, and hence dioramas, can be seen as existing not only in the form of tangible three-dimensional objects but also as the mental representations of complex ideas or systems (Gilbert \& Priest, 1997; Clement, 2000). Despite this, as Moormann and Bélanger note, research in science education about models has shown that students often understand models to be replicas of reality rather than as instruments within an epistemological process. This leads to Moormann and Bélanger's second question: How can dioramas promote modelbased learning?

The process starts from the act of museum designers and educators who transform scientists' consensus models into museographic target models. As visitors interact with dioramas taken as museographic models, mental models can gradually develop. Moormann and Bélanger have started exploring the learning about models that occurs during a school visit at the Museum für Naturkunde Berlin. Using concept maps and group discussions, they have been able to describe different forms of conceptual change with regard to students' understandings. Using the museum-derived framework, they plan to look at the gradual transformation of the students' mental models about natural ecosystems through repeated and varied encounters with dioramas.

Michael May's and Marianne Achiam's interest in Chapter 7 is on the specific mechanisms that enable the educational potential of dioramas to be realised. As they put it: "museum practitioners and museum researchers know that dioramas work, we just don't know how they work". They begin by noting that designers and curators tend to conceptualise museum visits as the communication of design intentions to visitors, mediated by exhibits, labels, explanatory signs and narratives. However, from the museum visitor's point of view, the experience can best be described as a meeting with artefacts or natural objects on display. As we all know, meetings can take place with little worthwhile communication occurring.

The inquiry aspect of a museum visit arises when visitors are confronted with exhibited objects they cannot immediately identify or with situations they do not understand. This can set in motion a sequence of actions such as looking for information on labels or explanatory signs next to a diorama. As a naturalistic or pseudo-naturalistic display of objects (e.g. humans, animals, plants, machines) in their natural or cultural environment, dioramas and their interpretation can appear straightforward, but, argue May and Marianne, complexity hides behind the naturalistic surface.

May and Achiam draw on the basic Gestalt principles formulated by Max Wertheimer almost 100 years ago. According to the proximity principle we experience objects that are spatially close as meaningfully grouped together, and according to the similarity principle we experience objects that are visually similar in shape, size or colour as meaningfully grouped together. Equally, we divide views into foregrounded figures and the background.

Furthermore, we extrapolate from what we see, attempting to give meaning to what is before us, as indicated by the principle of continuation, whether spatially or temporally.

These principles are important for how we understand dioramas. A moment in time showing, for example, the tiger diorama from the Natural History Museum in Helsinki (Figure 7.2) is read by us as a tiger attacking a deer (or a deer being attacked by a tiger, depending on our literal and metaphorical point of view) even though such a phrase indicates a considerable passage of time and a degree of intentionality. In other words, we extrapolate from what is in front of us; we generate a narrative to make sense of what we see, imagining both a past and a future rather than restricting ourselves to the present before us. Of course, such behaviour is 
honed by our evolutionary past (Abrahams \& Reiss, 2012). Early humans who failed to presume that a large predator in mid-air close by them might best be avoided did less well than those who did so presume.

There are educational risks in all this. As May and Achiam point out, given that the learning potential of the diorama arises from the imaginative richness of the content it creates by placing artefacts and natural objects within a naturalistic scene, one potential problem is that the naturalistic articulation of the diorama and its power to generate stories creates an apparent realism that could entail false inferences. This suggests an important role for a teacher in helping visitors understand the relationships between the diorama in front of them, their readings of it and, returning to Moormann's and Bélanger's point in Chapter 6, the reality that the diorama is attempting to model.

In Chapter 8, Edward Mifsud proposes that Engeström's (1999) Activity Theory can profitably be used to illuminate what is going on when a visitor attempts to interpret a museum diorama. Engeström's Activity Theory itself derives from the classic early work of the Russian psychologists Vygotsky, Leont'ev and Luria. One of the key points of Activity Theory is that it takes seriously the fact that the learning of individuals does not take place in isolation: learning is embedded in social relationships, so that we need to consider each individual, the objects of their learning and the social context in which learning takes place.

Mifsud applied his model to to data obtained from a subject, a nine-year-old boy, Jeremy, in the fifth year of primary school, who was observing a sand dune diorama in Malta (Figure 8.4), the artefact. The group is his class, particularly the pupils with whom he was experiencing the diorama. The diorama shows various birds, some reeds and a prominent Maltese boat resting on a bed of sand. Jeremy observes the diorama, which acts as a mediating tool to aid in his interpretation of the sand dune habitat it represents. He does this in the company of his peers, which may influence the way he sees the diorama and what he notices.

Mifsud uses drawings to help reveal the mental models of those at the diorama. Comparison of the expressed models with the original model helps revel the importance of previous knowledge. Malta is, of course, a relatively small island and so Jeremy was previously familiar with seaside habitats.

While the strength of the model lies in how it links together the elements involved in the interpretation of an artefact (in this case a diorama), Mifsud lists a number of limitations, though some of these seem to be more to do with his model than with the use of Activity Theory.

In Chapter 9, Debra McGregor and Jennifer Gadd move the focus to how beginning teachers can be supported to help children understand the work of natural history scientists. Instead of undertaking work at existing professionally made dioramas - the standard approach in educational research on dioramas - McGregor and Gadd got beginning teachers to make their own small dioramas.

The beginning teachers were in the second year of a Batchelor of Arts (Educational Studies) undergraduate degree course. A total of 71 such students were split into three (successive) teaching groups and took part in a specially designed workshop in which they mostly worked in triads. Each such group of three students was given a card with the name of one of the 
natural history scientists named in the 'notes' section of the latest science National Curriculum in England: Mary Anning, David Attenborough, Rachel Carson, Charles Darwin and Jane Goodall. They were also given a shoe box within which to create a diorama, and a range of everyday modelling materials such as paper, card, tissue, coloured cellophane, paints, hot glue guns and cutting knives. The students were asked not to divulge which scientist they had been allocated; their task was to 'reveal' their scientist through their diorama. Finally, they were asked to create their own success criteria for their displays, taking into account what they might expect a primary school child to achieve during the activity.

As they constructed their dioramas, the students were provided with a tablet computer connected to the internet to help them research their scientist. The tutors (Debra McGregor and Jennifer Gadd) moved from group to group collecting field notes and taking photographs to document the artefact construction process. Once the building-dioramas phase was complete the beginning teachers then took time to visit and review the other dioramas, as if at a local museum reviewing the display boxes.

Unsurprisingly, the evaluation revealed that the students enjoyed the activity and most of them indicated that they learned much more about the lives and work of natural history scientists. The dioramas illustrated how the groups focused on differing aspects of the scientists work. For example, and just with reference to Charles Darwin, one diorama highlighted his conclusions about the evolution of humans from (other) primates; another focused on his work, symbolised by an enlarged magnifying lens, on the beaks of finches on the Galapagos Islands; a third looked at variation in the general morphology of the finches. Darwin was well known to the students; at the other extreme, not a single one of the 71 said they had heard of Rachel Carson. From knowing nothing about her, the students came to realise that she possessed keen observational skills that informed her work on the causal relationship between pollution and damage to the reproductive capacity of organisms.

Interesting too were the students' views as to why dioramas were appropriate to use for learning. About half the students recognised a wide variety of learning processes involved in the construction and review processes of making the dioramas. They commented on the way that the collaborative learning processes were fun and involved discussions, exchanges of ideas and negotiations about what to include and how to make the displays. They realised that researching for relevant information and considering ways to use resource materials creatively to represent relevant ideas that illustrated and summarised understandings all involved critical and in-depth thinking. Some thought that using dioramas for learning could promote motor and design skills.

Cristina Trowbridge is a senior manager of professional development at the American Museum of Natural History. Initially she did not use dioramas much in her work but she wanted to help teachers harness the potential for interactive learning inherent in the museum setting. In 2009, she met Amy Chase-Gulden who taught her Visual Thinking Strategy (VTS); this changed her way of interacting with the dioramas and in turn how she worked with teachers and students.

Visual Thinking Strategy (VTS) is an interpretive method that is utilised more in art museums than in natural history museums. Traditionally, VTS is used in a group setting while looking at art and is facilitated by three guiding questions: What is going on in this picture?, What do you see that makes you say that? and What more can we find? VTS is 
intended to create a non-judgemental, facilitating environment that removes the risk of failure, welcomes plurality of perception, evokes curiosity and invites engagement.

Trowbridge added a sketching component to VTS, which proved to be a successful modification, and in Chapter 10 relates some of her experiences. She found that VTS with sketching helped teachers and students to engage in careful observation, an important component of science. It had other benefits too. As one first year teacher working with predominately second language learners in an Earth Science high school class put it:

Like meditation, it required focus, but was enjoyable. It was meaningful to pay attention to small details that would normally go overlooked. It created an allotment of time that was reserved for silence and peace. It forced us to have a break from the busy schedule of teaching to relax and focus on detail. Specifically since induction had a lot of discussion on the challenges of teaching, and was the ending of a stressful workweek. It was a great stress releaser that kept my mind active. I've thought about going to the museum on the weekend to draw some of the dioramas.

Additionally, the approach modelled other key aspects of the nature of science, namely inference and the formulation of hypotheses. Trowbridge concluded that the use of VTS and sketching with natural history dioramas offers new science teachers a readily replicable process for engaging students in direct observation of and inquiry about representations of natural phenomena.

In Chapter 11, Sue Dale Tunnicliffe, Rebecca Gazey and Eirini Gkouskou point out that in many early years settings, the educators, be they carers, primary/elementary teachers or chaperones on school field trips, are not confident in their own understanding when teaching physical science. Natural history dioramas therefore offer the promise of providing a more accessible route into physical science concepts, e.g. forces, than if such concepts are approached as they usually are, without the mediation of a biological context. Indeed, visitors at natural history dioramas often comment about such elements of physical science as the movement of animals. Other physical science concepts that may be facilitated by natural history dioramas include those of balance, the reflection of light, centre of gravity and heat loss.

In a workshop undertaken with two 11year-old boys at the Powell-Cotton Museum, the boys were asked, after viewing the Watering Hole diorama (Figure 11.3), to make a four-legged animal that could stand upright, using modeling clay (for the body) and cocktail sticks (for the legs). One boy immediately made a flat (horizontal) cuboid and fixed four legs, one at each corner of the body. The other boy decided to make an animal with a vertical cylindrical body. It was not easy to get this animal to stand up. He decided to reorient the 'body' so that he had a rectangular one that lay horizontally. Then he fixed the kegs together in the middle of the underside of the 'body'. Eventually he decided to try positioning the legs at the four corners and was pleased to find that this produced a stable model. The boys were invited to stand their 'animals' on a pack of cards which acted as a 'wobble' board and to investigate for how long their animal stood as more and more backward and forward movements of the board were made. They found that by having the legs not coming down vertically from the body but splayed out, the animals were more stable. The boys were asked to add a neck and a head on their body and then show how the giraffe-like model animal could drink. By simulating it visiting The Watering Hole, they found that the animal toppled over until they had increased the distance between the bottom of the legs. They remembered they had learnt 
about forces in school science but said that that had not related to anything in their everyday world.

On returning to the diorama, the boys added these science ideas of balance, stability and centres of gravity to their interpretation of the diorama. One of the boys reported that "the giraffe starts bending her legs to get her head closer to the ground. I can see stability in the animals. The legs support the position of the head. Each part of the body supports because, for example, one leg of the giraffe cannot work without the other legs".

Finally, in Chapter 12, Jesús Piqueras, Karim Hamza and Susanna Edvall present an analysis of student teachers' moment-by-moment learning during a teaching activity at a diorama at the Swedish Museum of Natural History in Stockholm. The diorama showed a female whitetailed eagle eating the remains of a roe deer in a snowy landscape in the presence of crows (Figure 12.1). An interview with the curator showed that the main intention of the diorama was to show the co-operative behavior of the crows as they attempt to steal food from the eagle. Another curatorial aim was to challenge the curiosity and imagination of the visitors by placing additional details and clues in the main scene. Thus, there are yellow spots and footprints interspaced on the snow, resulting from a presumptive fox that has visited the carrion before the eagle and the crows; indeed, the head of the roe deer is missing (a common behavior of foxes is to take away the head of the animals they predate). The diorama was inspired by a real event shown in a short video sequence on a monitor screen close to the diorama. However, this resource was kept hidden from the student teachers during the activity.

The ten student conversations at the diorama lasted an average of twelve minutes in duration. Piqueras, Hamza and Edvall state that, to their surprise, the conversations were rarely related to the curatorial intention of the diorama but this is, I think, not unexpected for two reasons. First, few visitors, even student teachers, are likely to know anything about the way in which crows attempt to steal food from eagles whereas they are likely to know at least something about the way in which eagles eat carrion. Secondly, the decision was made not to allow the student teachers to view the video sequence on the nearby monitor screen, thus requiring the students to construct a narrative entirely from their own knowledge and presumptions.

\section{Conclusions}

Having read the chapters in this volume, I have come to three main conclusions.

The first, one that I share with all the authors, is that natural history dioramas have tremendous educational potential. As has often been noted, such dioramas are engaging to many visitors, whatever their age and prior knowledge and experience. Natural history dioramas enable visitors to construct narratives about what is happening.

The second, somewhat less positive, conclusion is that there remains a paucity of evidence as to the extent and types of learning that natural history dioramas afford. This, of course, is a spur to further research.

The third conclusion is that there exists quite a wide range of research tools for gathering and analysing data about the learning that takes place at dioramas. Some will welcome this 
pluralism; others will wonder whether it tells us more about those undertaking such research than anything else.

\section{References}

Abrahams, I. \& Reiss, M. (2012) Evolution. In: The Routledge International Handbook of Learning, Jarvis, P. with Watts, M. (Eds), Abingdon: Routledge, pp. 411-418.

Clement, J. (2000) Model based learning as a key research area for science education. International Journal of Science Education, 22, 1041-1053.

Gilbert, J. K. \& Priest, M. (1997) Models and discourse: a primary school science class visit to a museum. Science Education, 81, 749-762.

Millar, R. \& Osborne, J. (Eds) (1998) Beyond 2000: Science education for the future. London: Nuffield Foundation.

Miller, J. (1983) Scientific literacy: a conceptual and empirical review. Daedalus, 112(2), 2948.

Reiss, M. J. (2007) What should be the aim(s) of school science education? In: The reemergence of values in science education, Corrigan, D., Dillon, J. and Gunstone, R. (Eds), Rotterdam: Sense, pp. 13-28.

Reiss, M. J. \& Tunnicliffe, S. D. (2011) Dioramas as depictions of reality and opportunities for learning in biology. Curator, 54, 447-459.

Reiss, M. J. \& White, J. (2013) An aims-based curriculum: The significance of human flourishing for schools. London: IOE Press.

Tunnicliffe, S. D. (2005) What do dioramas tell visitors? A study of the History of the Forests diorama at the Museum of Scotland. Current Trends in Audience Research and Evaluation, 18, 23-31.

Wonders, K. (1993) Habitat dioramas: Illusions of wilderness in Museums of Natural History. Uppsala: Uppsala University Press. 